\title{
JAROSITA E PLUMBOJAROSITA NOS GOSSANS DO DISTRITO MINEIRO DE CANOAS (PR)
}

\author{
SÔNIA MARIA BARROS DE OLIVEIRA*, ALAIN BLOT**, ROSELY APARECIDA LIGUORIIMBERNON* \& \\ PHILIPPEMAGAT***
}

\begin{abstract}
JAROSITE AND PLUMBOJAROSITE IN GOSSANS OF THE CANOAS DISTRICT, PARANA STATE Jarosites and plumbojarosites in gossans related to $\mathrm{Pb}-\mathrm{Zn}$ mineralization in the Canoas Distríct are descríbed. They are always associated with goethite and in a minor extent with hematite. Some crystals show zoning with a core of jarosite and a rim of plumbojarosite. Others are rather homogeneous with intermediate composition. In the general formula $\left.\mathrm{AB}_{3}\left(\mathrm{SO}_{4}\right)_{2} \mathrm{OH}\right)_{6} \mathbf{A}$ sites are occupied by $\mathbf{K}$ and $\mathrm{Pb}$ and $\mathbf{B}$ sites by $\mathrm{Fe}, \mathrm{Al}$ and Zn. A and B sites are often incompletely filled. A sites generally show excess of charge. B sites show deficiency. Jarosites and plumbojarosites are secondary minerais formed by sulfur, iron and lead derived from the weatheríng of sulphides, and potassium from the gangue mineral orthoclase. The jarosite-goethite association in gossans percolated by meteoric waters is thermodynamically unstable. It persists due to the sluggishness of the transformation of the jarosite into goethite. Thus, the Canoas Jarosites are transitory $\mathrm{Pb}$ bearing phases. In the mature gossans $\mathrm{Pb}$ is associated only with the oxyhydroxides.
\end{abstract}

Keywords: jarosite, plumbojarosite, gossan

RESUMO São caracterizados, neste trabalho, jarosita e plumbojarosita em perfis de alteração do tipo gossan, provenientes do intemperismo de níveis mineralizados ricos em galena, esfalerita e pirita, contidos na sequência metapelítica da Formação Perau. Esses sulfatos encontram-se sempre associados à goethita e subordinadamente à hematita. Ocorrem seja como cristais zonados, com núcleo de jarosita e borda de plumbojarosita, seja como cristais homogéneos de composição intermediária. Apresentam fórmula geral $\mathrm{AB}_{3}\left(\mathrm{SO}_{4}\right) 2(\mathrm{OH})_{6}$ onde $\mathbf{A}$ é ocupado por $\mathrm{K}$ e $\mathrm{Pb}$, e $\mathbf{B}$ por $\mathrm{Fe}, \mathrm{Al}$ e Zn. De modo geral, há vacância e excesso de carga em A, e vacância e deficiência de carga em $\mathbf{B}$. As jarositas e plumbojarositas são minerais secundários neoformados a partir da oxidação dos sulfetos primários que teriam fornecido o ferro, enxofre e chumbo, e da hidrólise do ortoclásio da ganga que teria fornecido o potássio. A associação jarosita-goethita num gossan percolado pelas águas meteóricas é, do ponto de vista termodinâmico, instável, e só se mantém devido à lentidão da transformação, da jarosita em goetnita. Assim, as jarositas de Canoas não passam de uma armadilha provisória para 0 chumbo, que acaba se associando exclusivamente à goetnita nos gossans mais maduros.

Palavras-chave: jarosita, plumbojarosita, gossan

INTRODUÇÃO A jarosita e a plumbojarosita pertencem à família da alunita-jarosita, de fórmula geral $\mathrm{AB}_{3}\left(\mathrm{XO}_{4}\right) 2(\mathrm{OH})_{6}$, onde $\mathrm{A}$ representa um cátion grande de coordenação dodecaédrica $\left(\mathrm{H}_{3} \mathrm{O}^{+}, \mathrm{Na}^{+}, \mathrm{K}^{+}, \mathrm{Rb}^{+}, \mathrm{Ag}^{+}, \mathrm{NH}_{4}^{+}\right.$, $\mathrm{Pb}^{2+}, \mathrm{Hg}$ ) e $\mathrm{B}$ um cátion menor, de coordenação octaédrica $\left(\mathrm{Fe}^{3+}, \mathrm{Al}^{3+}, \mathrm{Cu}^{2+}, \mathrm{Zn}^{2+}\right)$. O ânion $\mathrm{XO}_{4}^{\mathrm{y}^{-2}}$ pode ser $\mathrm{SO}_{4}^{2-}, \mathrm{PO}_{4}^{3-}$, $\mathrm{AsO}_{4}{ }^{3--}, \mathrm{CO}_{3}^{2-}, \mathrm{SbO}_{4}, \mathrm{CrO}_{4}^{3-}$ ou $\mathrm{SiO}_{4}^{4-}$. Baseando-se na natureza dos ânions, a família divide-se em três grandes grupos: grupo da alunita com 2 ânions $\mathrm{XO}_{4}$ divalentes (sulfatos) e geralmente cátions A monovalentes, grupo da woodhouseíta, com um ânion $\mathrm{XO}_{4}$ divalente e outro trivalente (sulfofosfatos ou sulfoarsenatos) e geralmente cátions A divalentes e, finalmente, o grupo da crandalita (fosfates ou arsenatos), com dois ânions $\mathrm{XO}_{4}$ trivalentes e cátions $\mathbf{A}$ divalentes ou trivalentes (Kato \& Miura 1977). No grupo da alunita, quando o sítio B é ocupado principalmente por $\mathrm{Al}$, os minerais são alunitas. Se por Fe, são jarositas, que se subdividem numa variedade de espécies em função do cátion que predomina no sítio A. Quando o sítio A é ocupado por $\mathrm{K}^{+}$, a espécie é jarosita, de fórmula $\mathrm{KFe}_{3}\left(\mathrm{SO}_{4}\right)_{2}(\mathrm{OH})_{6}$. Quando é ocupado por $\mathrm{Pb}^{2+}$, trata-se de plumbojarosita, de fórmula $\mathrm{Pb}_{0.5} \quad{ }_{0.5} \mathrm{Fe}_{3}\left(\mathrm{SO}_{4}\right)_{2}(\mathrm{OH})_{6}$.

A estrutura das alunitas e jarositas foi determinada por Hendricks (1937). Em termos simplificados, a estrutura é de folha, na qual os cátions trivalentes ( $\mathrm{Fe}$ e $\mathrm{Al}$ ) formam octaedros de $\mathrm{R}^{3+}(\mathrm{O}, \mathrm{OH})$ ligados pêlos vértices num plano paralelo a (001). Os três oxigênios apicais de cada tríade de octaedros formam a base para os tetraedros $\mathrm{XO}_{4}$. Essas camadas oc- taédrícas são empilhadas ao longo do eixo $c$, de modo a acomodar entre elas os cátions dodecaédricos como $\mathrm{K}^{+}, \mathrm{Na}^{+}$, $\mathrm{Sr}^{2+} \mathrm{Ou} \mathrm{Pb}^{2+}$. Assim, a substituição entre os cátions trivalentes afeta principalmente a dimensão $a$, enquanto a substituição entre os cátions de coordenação dodecaédrica afeta principalmente a dimensão $c$.

As jarositas pertencem ao grupo espacial romboédrico $\mathrm{R}^{3} \mathrm{~m}$ e são descritas em termos da cela hexagonal, na qual $a=7 \AA$ e $c=17 \AA$, aproximadamente, quando o cátion dodecaédrico é o K $\mathrm{K}^{+}$. No caso da plumbojarosita, o balanço de carga é obtido porque apenas metade dos sítios $\mathrm{A}$ é ocupada pelo $\mathrm{Pb}^{2+}(50 \%$ de vacância em A); o eixo c, portanto, dobra (aproximadamente $34 \AA)$, e a fórmula torna-se $\mathrm{Pb}\left[\mathrm{Fe}_{3}\left(\mathrm{SO}_{4}\right)_{2}(\mathrm{OH})_{6}\right]_{2}$, que é equivalente a $\mathrm{Pb}_{0,5}{ }_{0.5} \mathrm{Fe}_{3}\left(\mathrm{SO}_{4}\right)_{2}(\mathrm{OH})_{6}$ (Jambor \& Dutrizac, 1983).

Esses minerais ocorrem numa grande variedade de ambientes geológicos (Brophy \& Sheridan 1964), mas são mais comuns em áreas de hidrotermalismo ativo (Allen et al. 1935, Johnston 1977) e nas porções oxidadas dos perfis de alteração intempérica sobre formações sulfetadas (Amorós et al, 1981; Taylor \& Appleyard 1983; Scott 1987; Oliveira et al., 1993).

Em Canoas, as jarositas ocorrem em gossans derivados da oxidação de níveis sulfetados ricos em galena, esfalerita e pirita, encontrando-se sempre intimamente associadas à goethita. O objetivo deste trabalho é o de caracterizar esses materiais do ponto de vista mineralógico e geoquímico, estabelecer sua gênese e discutir os aspectos termodinâmicos e cinéticos de sua presença nos gossans.

* Instituto de Geociências da Universidade de São Paulo (IGUSP)/Núcleo de Pesquisas Geoquímicas e Geoffsicas da Litosfera (NUPEGEL) Rua do Lago, 562, Cidade Universitária - São Paulo. Caixa Postal 11348 São Paulo CEP 05422-970, Tel (011) 8183917.

** Institut Francais de Recherche Scientifique pour lê Développement en Coopération (ORSTOM) 32, Av. Henri Varagnat, 931 í43 Bondy, Cedex, França. Tel. 48025500 .

***ORSTOM/NUPEGEL 
CONTEXTO GEOLÓGICO O distrito mineiro de Canoas, situado no município de Adrianópolis, estado do Paraná, junto à divisa do estado de São Paulo (Fig.l), compreende vários corpos mineralizados, totalizando 525.000 ton de minério com teor médio de $3,1 \%$ de $\mathrm{Pb}, 3,1 \%$ de $\mathrm{Zn}$ e $60 \mathrm{~g} / \mathrm{ton}$ de $\mathrm{Ag}$ (Queiroga, N., com. oral). Dois corpos já estiveram em exploração, Canoas 1, entre 1985 e 1991 e Canoas 2 entre 1991 e 1995. O minério está contido na sequência metapelítico-carbonática da Formação Perau, sendo composto por sulfetos (pirita, galena e esfalerita, associadas a menores quantidades de calcopirita e pirrotita) disseminados principalmente em determinados leitos ao longo da foliação (Daitx \& Venusso 1992). Quando os leitos mineralizados afloram, são intensamente afetados pelo intemperismo, resultando em gossans, que contêm os seguintes minerais: goethita, hematita, smithsonita, jarosita, plumbojarosita, clorita zincífera e traços de cerussita e piromoffita, além dos minerais da ganga, principalmente quartzo, barita, talco e acessoriamente ortoclásio.

Para este trabalho, foi amostrado um afloramento situado sobre a galeria de entrada da mina abandonada de Canoas 1 . As jarositas ocorrem como um material de coloração amarelada, disperso no seio de uma massa terrosa avermelhada de composição essencialmente goethítica. Apesar do esforço no sentido de separar as porções mais amareladas, as amostras coletadas sempre estavam contaminadas, em maior ou menor proporção, por goethita.

MÉTODOS Os fragmentos amostrados foram impregnados com resina epoxy para permitir a laminação. As seções delgadas foram polidas para exame ao microscópio óptico e ao microscópio eletrônico de varredura equipado com microanalisador EDS, no Laboratório de Microscopia Eletrônica da ORSTOM, França.

Uma parte das amostras foi moída a -200 mesh para análise química de maiores e traços, duração de raios $X$, análise termo-diferencial e espectroscopia Mössbauer.

Os difratogramas de raios $X$ foram obtidos usando um difratômetro Philips, equipado com monocromadorde grafite e tubo de $\mathrm{Cu}$. O registro foi efetuado passo a passo, à velocidade de $0,040^{\circ} 20715$ seg., de $5^{\circ}$ a $120^{\circ}$. Os parâmetros da cela unitária da jarosita foram calculados pelo método de Rietveld, a partir do programa DBWS-9411 (Young et al. 1995).

Um espectro Mössbauer foi obtido a $78 \mathrm{~K}$, usando um espeetrômetro convencional de aceleração constante e fonte $\mathrm{Rh}$ (57Co), no Instituto de Física da Universidade de São Paulo. A pastilha foi preparada, pressionando a amostra entre duas placas de lucita para atingir a espessura de $10 \mathrm{mg} / \mathrm{cm}^{2} \mathrm{Fe}$. $\mathrm{O}$ espectro foi ajustado a funções gaussianas por um algorítimo de quadrados mínimos não lineares.

A curva térmica foi obtida num equipamento Netzsche, na ORSTOM, França. A velocidade de aquecimento foi de $10^{\circ} \mathrm{C} / \mathrm{min}$.

As análises químicas multielementares do material moído foram realizadas por ICP precedido de fusão para os elementos maiores, e ICP precedido de digestão ácida para os elementos traços (Activation Laboratories Ltda., Ancaster, Ontario, Canada).

RESULTADOS E DISCUSSÃO O estudo microscópico das lâminas delgadas mostrou que a jarosita ocorre sempre associada à goethita, podendo apresentar-se em cristais de forma acicular bem desenvolvidos, medindo até $50 \mu \mathrm{m}$ de comprimento (Fig.2). Ao microscópio eletrônico de varredura, a jarosita aparece em cristais de alguns micrômetros de diâmetro, com forma pseudo-hexagonal bem característica (Fig.3), geralmente envolvidos por goethita microcristalina (Fig.4).
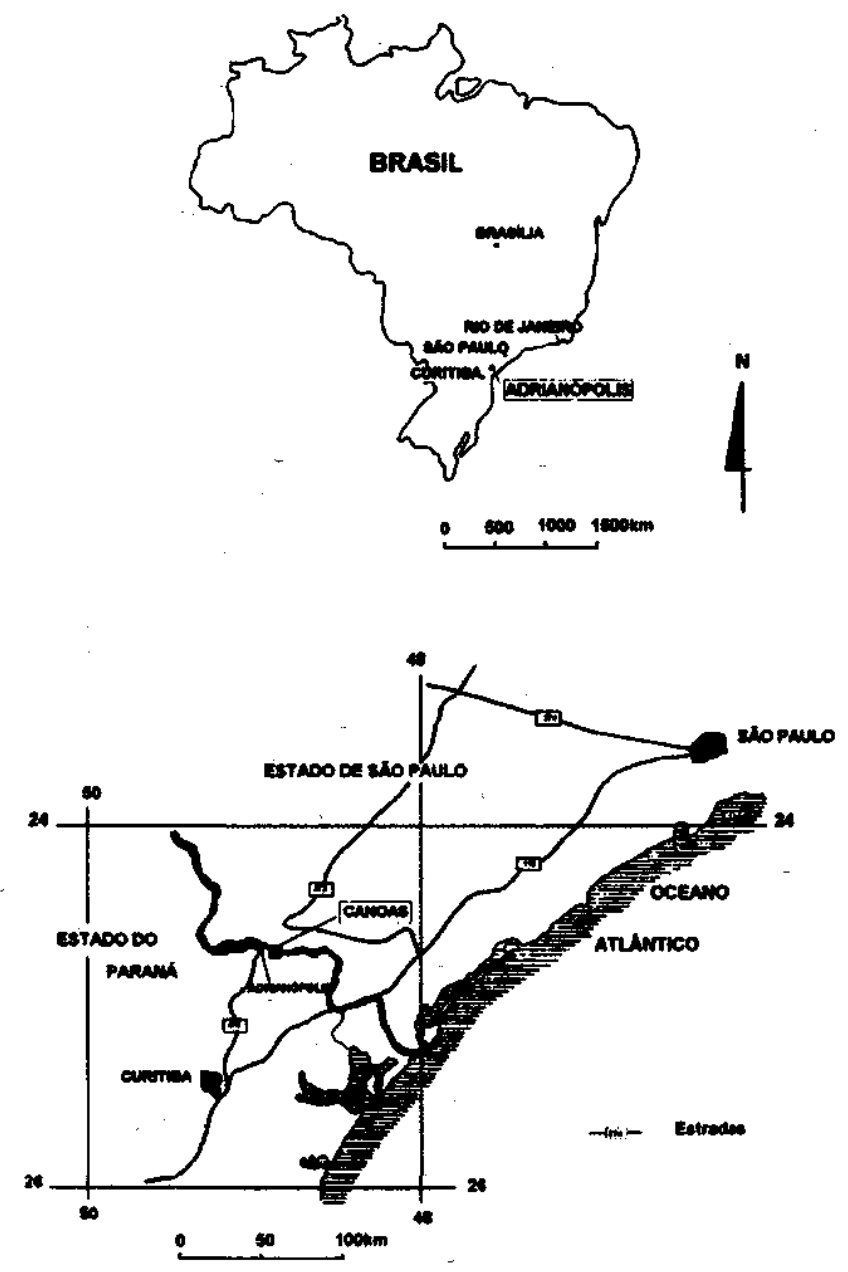

Figura 1 -Mapa de localização da área estudada. Figure $1 \cdot$ Location map of the studied área.

O padrão difratométrico é típico da jarosita. A Tabela 1 mostra as distâncias interplanares e as intensidades relativas dos picos obtidos para a jarosita de Canoas e os valores correspondentes para as jarositas sintéticas de Dutrizac \& Kaiman (1976) e para a jarosita ASTM. Digno de nota é a presença de um pico de fraca intensidade, correspondente à distância interplanar de 11,28 $\AA$ (003). Segundo Jambor \& Dutrizac (1983), a presença desse pico não é fenómeno raro. Embora típico de plumbojarosita com $c=34 \AA$ aproximadamente, pode ocorrer tanto em jarositas sintéticas com quantidades variáveis de $\mathrm{Pb}$, como em jarositas naturais essencialmente potássicas, o que sugere, segundo esses autores, que alguns dos conceitos sobre a estrutura cristalina das jarositas necessitam revisão. No caso da jarosita de Canoas, o cálculo dos parâmetros da cela unitária forneceu os valores de $a=$ $7,299 \AA$ e $c=17,172 \AA$. Esses valores não diferem muito daqueles fornecidos para a jarosita puramente potássica de Brophy \& Sheridan (1964): $a=7,288$ A e $c=17,192 \mathrm{~A}$.

A determinação da composição química global de uma amostra de jarosita contendo também alguma goethita e hematita (E 506), permitiu o cálculo da fórmula estrutural para a jarosita:

\section{$\left(\mathrm{K}_{0,59} \mathrm{~Pb}_{0,09} \mathrm{Na}_{0,04} \square_{0,28}\right)\left(\mathrm{Fe}_{2,90} \mathrm{Al}_{0,10}\right)\left(\mathrm{S}_{1,98} \mathrm{P}_{0,02} \mathrm{O}_{4}\right)_{2}(\mathrm{OH})_{6}$}

O procedimento adotado para o cálculo foi o proposto por Scott (1987), com base em dois moles de $\mathrm{XO}_{4}$. O sítio B foi calculado na base de três moles, excluindo-se o excedente de 


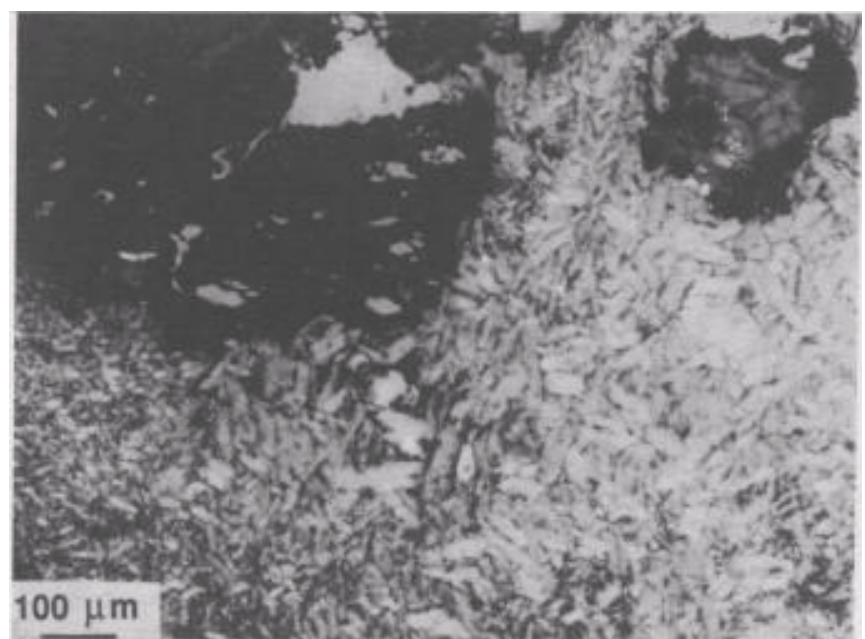

Figura 2 - Fotomicrografia de cristais aciculares dejarosita. Figure 2 - Photomicrograph of acicular crystals of jarosite.
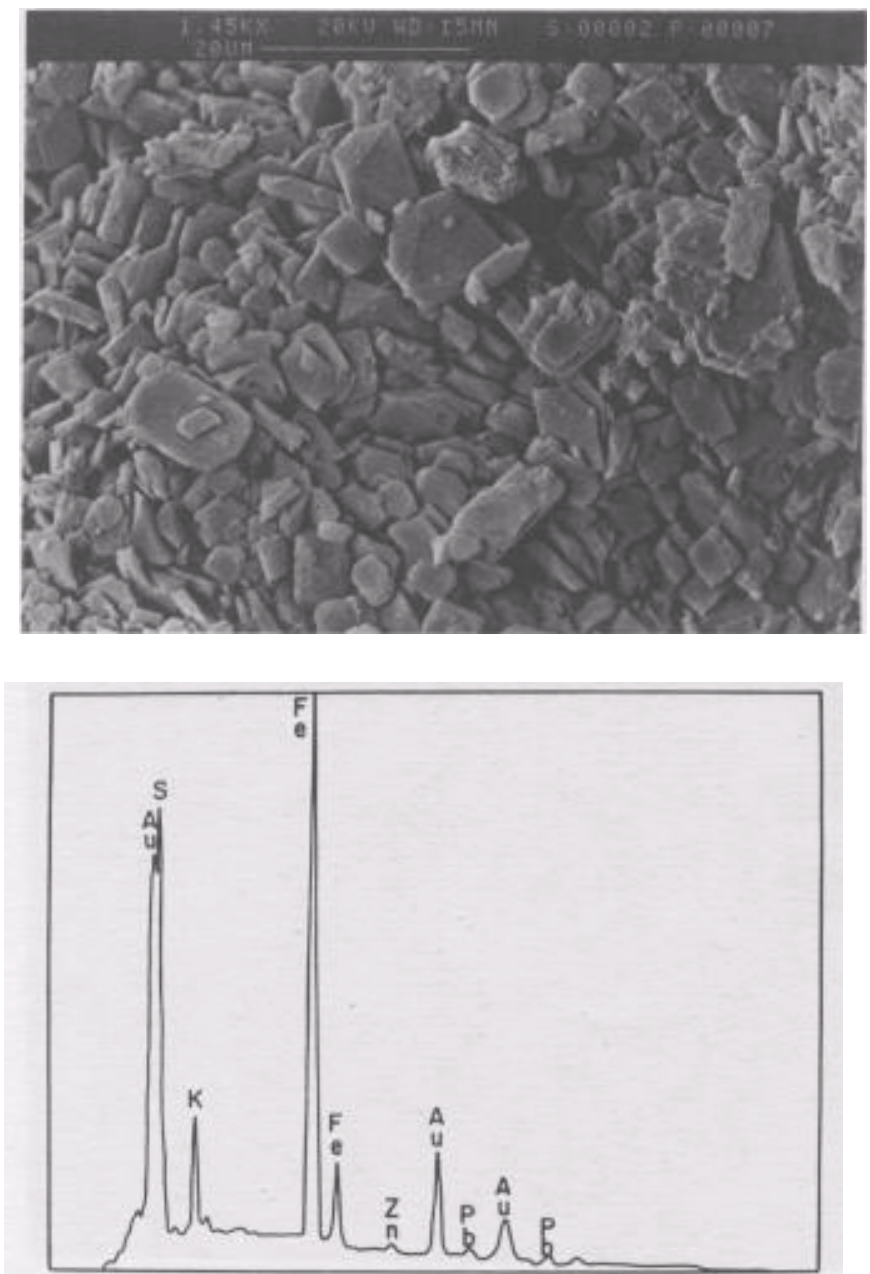

Figura 3 - Cristais dejarosita ao MEV (elétrons secundários). Espectro EDS dajarosita.

Figure 3 - SEM (secondary electrons) image of jarosite. EDS spectrum of jarosite.

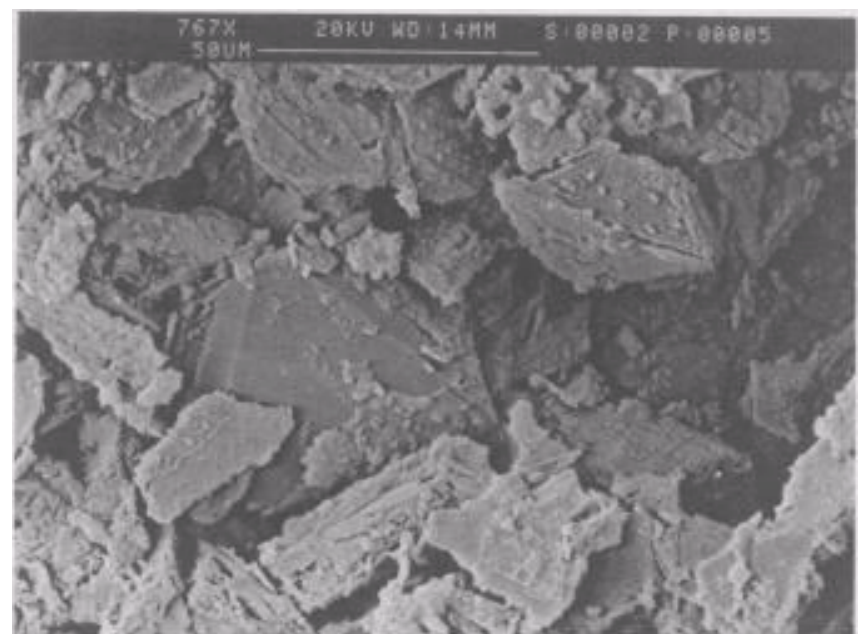

Figura 4 - Jarosita associada à goethita ao MEV (elétrons secundários).

Figure 4 - SEM (secondary electrons) image of jarosite associated with goethite.

Tabela $l$ - Dados de difração de raios X para jarositas de Canoas, jarosita ASTM, e jarositas sintéticas: 1 - K-jarosita e $2=$ Pb-jarosita (Dutrizac \& Kaiman, 1976).

Table 1 - X ray diffraction data for Canoas jarosite, ASTM jarosite and synthetic jarosites: $1=\mathrm{K}$-jarosite and $2=\mathrm{Pb}$-jarosite (Dutrizac \& Kaiman, 1976).

\begin{tabular}{|c|c|c|c|c|c|c|c|}
\hline \multicolumn{2}{|c|}{$\begin{array}{c}\text { Jarosita } \\
\text { Canoas }\end{array}$} & \multicolumn{2}{c|}{$\begin{array}{c}\text { Jarosita } \\
\text { ASTM }\end{array}$} & \multicolumn{2}{c|}{$\begin{array}{c}\text { Jarosita } \\
\text { Sint.(1) }\end{array}$} & \multicolumn{2}{c|}{$\begin{array}{c}\text { Jarosita } \\
\text { Sint.(2) }\end{array}$} \\
\hline $\mathrm{d} \AA$ & $\mathrm{I} / \mathrm{Io}$ & $\mathrm{d} \AA$ & $\mathrm{I} / \mathrm{lo}$ & $\mathrm{d} \AA$ & I/lo & $\mathrm{d} \AA$ & I/o \\
\hline 11.28 & 4 & - & - & - & - & - & - \\
5.95 & 36 & 5.94 & 30 & 5.96 & 30 & 5.95 & 40 \\
5.74 & 22 & 5.74 & 20 & 5.71 & 20 & 5.64 & 20 \\
5.10 & 35 & 5.09 & 40 & 5.10 & 70 & 5.09 & 50 \\
3.66 & 15 & 3.65 & 10 & 3.66 & 30 & 3.67 & 30 \\
3.11 & 43 & 3.11 & 60 & 3.12 & 60 & 3.12 & 50 \\
3.08 & 100 & 3.08 & 100 & 3.08 & 100 & 3.08 & 100 \\
2.97 & 12 & 2.97 & 10 & 2.98 & 5 & 2.98 & 20 \\
2.87 & 30 & 2.87 & 20 & 2.86 & 30 & 2.82 & 30 \\
1.98 & 30 & 1.98 & 50 & 1.94 & 10 & 1.93 & 10 \\
1.83 & 20 & 1.80 & 50 & 1.83 & 60 & 1.83 & 40 \\
1.58 & 2 & 1.54 & 30 & 1.54 & 30 & 1.75 & 5 \\
\hline
\end{tabular}

ferro, considerado como contaminação por goethita e hematita. $\mathrm{O}$ resultado indica uma jarosita quase que puramente potássica, com cerca de $30 \%$ de vacância no sítio A.

$\mathrm{O}$ espectro Mösbauer a $78 \mathrm{~K}$ para essa mesma amostra está mostrado na figura 5. Consiste de um dubleto acompanhado por dois sextetos. Os parâmetros do ajuste são apresentados na tabela 2. $\mathrm{O}$ primeiro sexteto pode ser atribuído à goethita (Forsyth et al. 1968) e o segundo à hematita (Kundig et al. 1966). Quanto à jarosita, a $78 \mathrm{~K}$ não há ordenação magnética para o aparecimento de um sexteto (Takano et al. 1969; Afanasev et al, 1974). O dubleto característico dajarosita de Canoas a essa temperatura apresenta um desdobramento quadripolar $(\Delta)$ de $1,28 \mathrm{~mm} / \mathrm{s}$ e um deslocamento isomérico

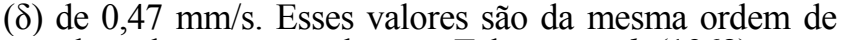
grandeza dos apresentados por Takano et al. (1968) e por Leclerc (1980) a temperatura ambiente, e por Afanasev et al. 


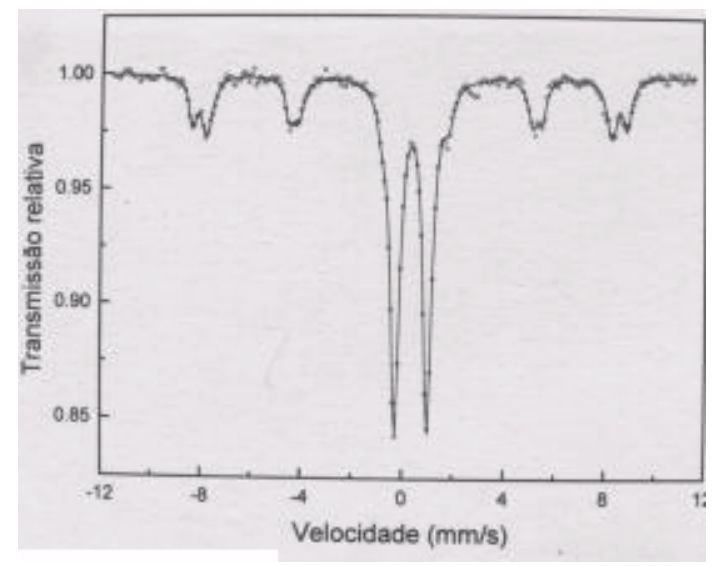

Figura 5 - Espectro Mössbauer a $78 \mathrm{~K}$ de jarosita associada a goethita e hematita (amostra E 506).

Figure 5 - Mössbauer spectrum at $78 \mathrm{~K}$ of jarosite associated with goethite and hematite (sample E 506).

Tabela 2 - Parâmetros de espectro Mössbauer para a amostra E 506 a $78 \mathrm{~K}$.

$\Delta=$ desdobramento quadripolar, $\delta=$ deslocamento isomérico, $\mathrm{Bhf}=$ campo hiperfino.

Table 2 - Mössbauer spectrum parameters at $78 \mathrm{~K}$ - Sample E 506

$\mathrm{A}=$ quadrupole splitting, $5=$ isomer shift, $\mathrm{Bhf}=$ hyperfine field.

\begin{tabular}{|c|c|c|c|c|c|}
\hline AMOSTRA & MINERAL & ÁREA $(\%)$ & $\Delta(\mathbf{m m} / \mathrm{s})$ & $\delta(\mathrm{mm} / \mathrm{s})$ & Bhf (kG) \\
\hline \multirow{2}{*}{ E S06 } & Jarosita & 60 & 1.28 & 0.47 & - \\
& Gxethita & 26 & -0.25 & 0.49 & 497 \\
& Hematita & 14 & -0.25 & 0.49 & 533 \\
\hline
\end{tabular}

(1974) a 77 K. A estimativa das áreas sob cada uma das curvas do espectro permite avaliar aproximadamente a distribuição do ferro nas diferentes fases. Segundo esses dados, apenas $60 \%$ do ferro total da amostra estaria na jarosita, estando o resto na goethita e na hematita (Tab. 2) Usando-se essa informação adicional, é possível dar uma melhor aproximação ao número de átomos de Fe na fórmula estrutural da jarosita. Assim, para $(\mathrm{S}+\mathrm{P})-2, \mathrm{Fe}=2,16$ e não 2,90 , como acima calculado. A fórmula estrutural da jarosita seria, portanto:

$$
\begin{aligned}
& \left(\mathrm{K}_{0,59} \mathrm{~Pb}_{0,09} \mathrm{Na}_{0,04} \square_{0,28}\right)\left(\mathrm{Fe}_{2,16} \mathrm{Al}_{0,10} \square_{0,74}\right)\left(\mathrm{S}_{1,98} \mathrm{P}_{0,02} \mathrm{O}_{4}\right)_{2} \\
& (\mathrm{OH})_{6 .}
\end{aligned}
$$

Essa proposta de fórmula estrutural para a jarosita da amostra E 506 será discutida mais adiante, com base nos dados químicos microsituados de outras quatro amostras.

A análise termo-diferencial de uma amostra de jarosita pura (Fig. 6) mostrou dois picos endotérmicos a $423^{\circ} \mathrm{C}$ e a $720^{\circ} \mathrm{C}$, além de um pequeno pico exotérmico a aproximadamente $500^{\circ} \mathrm{C}$ (Fig.6). Segundo Kulp \& Adler (1950), o primeiro pico

$$
\mathrm{K}_{2}\left[\mathrm{Fe}_{3}\left(\mathrm{SO}_{4}\right)_{2}(\mathrm{OH})_{6}\right]_{2} \rightarrow \mathrm{K}_{2} \mathrm{SO}_{4} \cdot \mathrm{Fe}_{2}\left(\mathrm{SO}_{4}\right)_{3}+2 \mathrm{Fe}_{2} \mathrm{O}_{3}+6 \mathrm{H}_{2} \mathrm{O}
$$

endotérmico corresponde à seguinte reação:

$\mathrm{O}$ pico exotérmico reflete a cristalização do $\mathrm{Fe}_{2} \mathrm{O}_{3}$, e o segundo pico endotérmico corresponde à quebra do $\mathrm{K}_{2} \mathrm{SO}_{4} \cdot \mathrm{Fe}_{2}\left(\mathrm{SO}_{4}\right)_{3} \mathrm{em} \mathrm{K}_{2} \mathrm{SO}_{4}+\mathrm{Fe}_{2} \mathrm{O}_{3}+3 \mathrm{SO}_{3}$.

Quatro seções delgadas polidas foram examinadas ao $\mathrm{MEV}$ e analisadas pontualmente por EDS. As duas primeiras (amostras F e G) apresentam cristais de até $20 \mu \mathrm{m}$ de diâmetro nitidamente zonados (Fig. 7). A micrografia de raios $\mathrm{X}$ de um desses cristais indica claramente tratar-se de um cristal com núcleo de jarosita e bordas de plumbojarosita (Fig. 8). O cálculo do número de átomos referidos a $\mathrm{XO}_{4}=2$ moles para os pontos analisados neste e noutros cristais igualmente zonados consta da Tabela 3. Para o cristal mostrado na figura 8, a fórmula estrutural média para a borda (F52, F55, F56) e para o núcleo (F46, F47, F48) é, respectivamente:

\section{$\left(\mathrm{K}_{0,07} \mathrm{~Pb}_{0,65} \square_{0,28}\right)\left(\mathrm{Fe}_{2,64} \mathrm{Al}_{0,02} \square_{0,34}\right)\left(\mathrm{SO}_{4 \mathrm{D}}\right)_{2}(\mathrm{OH})_{6} \mathrm{e}$ $\left(\mathrm{K}_{0,78} \mathrm{~Pb}_{0,13} \square_{0,09}\right)\left(\mathrm{Fe}_{2,63} \mathrm{Al}_{0,03} \square_{0,31}\right)(\mathrm{SO}$}

Cristais pseudo-hexagonais zonados de jarosita semelhantes aos de Canoas foram descritos na Tintic Standard Mine, em Utah, Estados Unidos. Szymansky (1985) descreveu dois cristais dessa mina com núcleo de jarosita e borda de plumbojarosita. Tambor \& Dutrizac (1983) mostraram outros cristais da mesma mina, com zoneamento mais complexo: núcleo de jarosita, camada intermediária de plumbojarosita e borda de natrojarosita. Em ambos os casos, trata-se de cristais de mais de $100 \mu \mathrm{m}$ de diâmetro, sendo, portanto, bem maiores que os encontrados em Canoas.

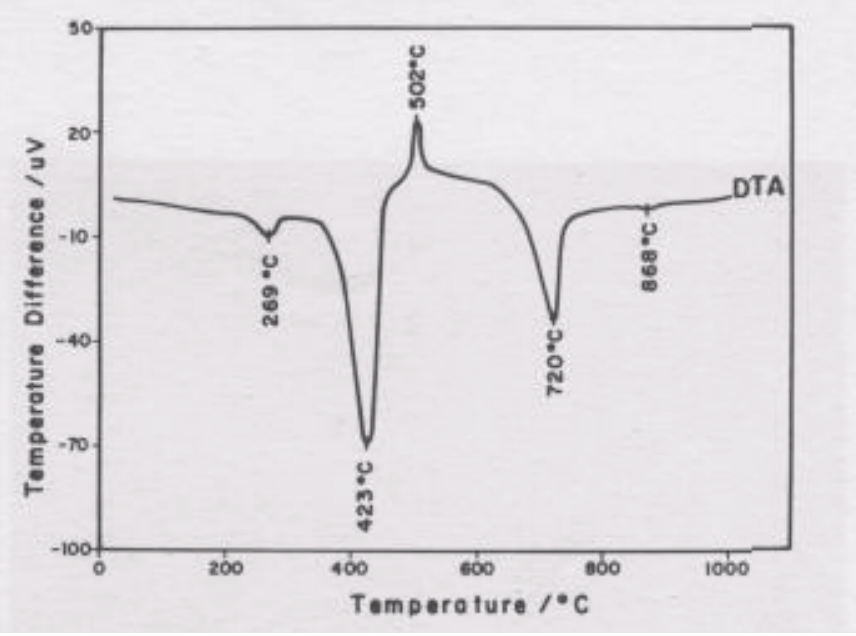

Figura 6 -Curva ATD da jarosita.

Figure 6 -DTA curve of jarosite.

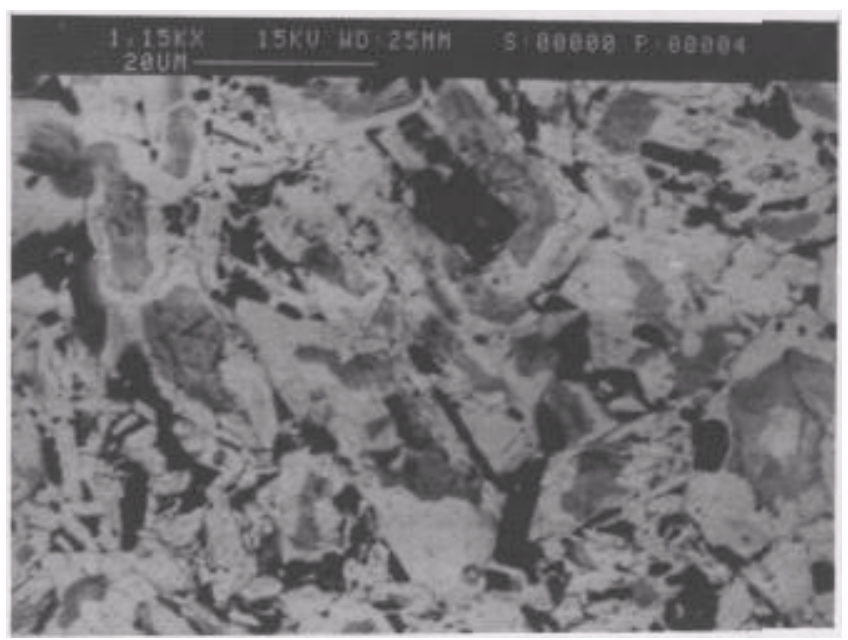

Figura 7 - Zoneamento em cristais de jarosita (amostra F) ao MEV (elétrons secundários).

Figure 7 - SEM (secondary electrons) image crystals of jarosite showing zoning (sample F). 
O diagrama da figura 9 mostra, para as amostras $\mathrm{F}$ e $\mathrm{G}$, a esperada correlação negativa existente entre os cátions mono e bivalentes da posição A. Também fica claro nesta figura a transição abrupta entre centro e borda dos cristais, indicada pelo evidente gap composicional. Os pontos analisados nos núcleos dos cristais com $\mathrm{A}^{+}$elevado estão próximos da reta $\mathrm{A}^{+}+2 \mathrm{~A}^{2+}=1$ e dela se afastam à medida que $\mathrm{A}^{2+}$ aumenta (Fig. 9). $\mathrm{O}$ total das cargas em $\mathbf{A}$ é próximo do valor teórico de 1 , dele se afastando à medida que $\mathrm{A}^{2+}$ aumenta (Fig. 10). Para as plumbojarositas das bordas dos cristais $\left(\mathrm{Pb}^{2+}\right.$ elevado), os pontos do diagrama situam-se sempre acima da reta $\mathrm{A}^{+}+$ $2 \mathrm{~A}=1$ (Fig. 9), e o total das cargas em A é sempre superior ao valor teórico de 1 (Fig. 10). Em média, para a jarosita do núcleo dos cristais, na posição $\mathbf{A}$ a vacância $\left[1-\left(\mathrm{A}^{+}+\mathrm{A}^{2+}\right)\right]$, ou (1 - ocupância) está em torno de 0,10 , o que corresponde a $10 \%$ dos sítios (Tab. 3), e há um ligeiro excesso de carga $\left(\mathrm{A}^{+}+2 \mathrm{~A}^{2+}=1,10\right)$. Para a plumbojarosita das bordas dos cristais, a vacância é, em média, cerca de 0,33 , ou $33 \%$ dos sítios (Tab. 3), portanto inferior ao valor teórico de 0,5 . Há, em média, excesso de carga: $\mathrm{A}^{+}+2 \mathrm{~A}^{2+}=1,26$.

Com relação ao sítio $\mathbf{B}$, não há praticamente diferença entre os núcleos e as bordas dos cristais. Ocupado quase que exclusivamente pelo $\mathrm{Fe}^{3+}$, apresenta vacância em torno de $10 \%$ (2,7 átomos em lugar de 3 ), como se vê na Tabela 3, e deficiência de carga, isto é, a carga total em B é, em média, 8 e, na quase totalidade dos casos, inferior ao valor teórico de 9 (Fig. 11). O déficit de carga em $\mathbf{B}$ não é compensado pelo excesso de carga em $\mathbf{A}$, de modo que o total das cargas

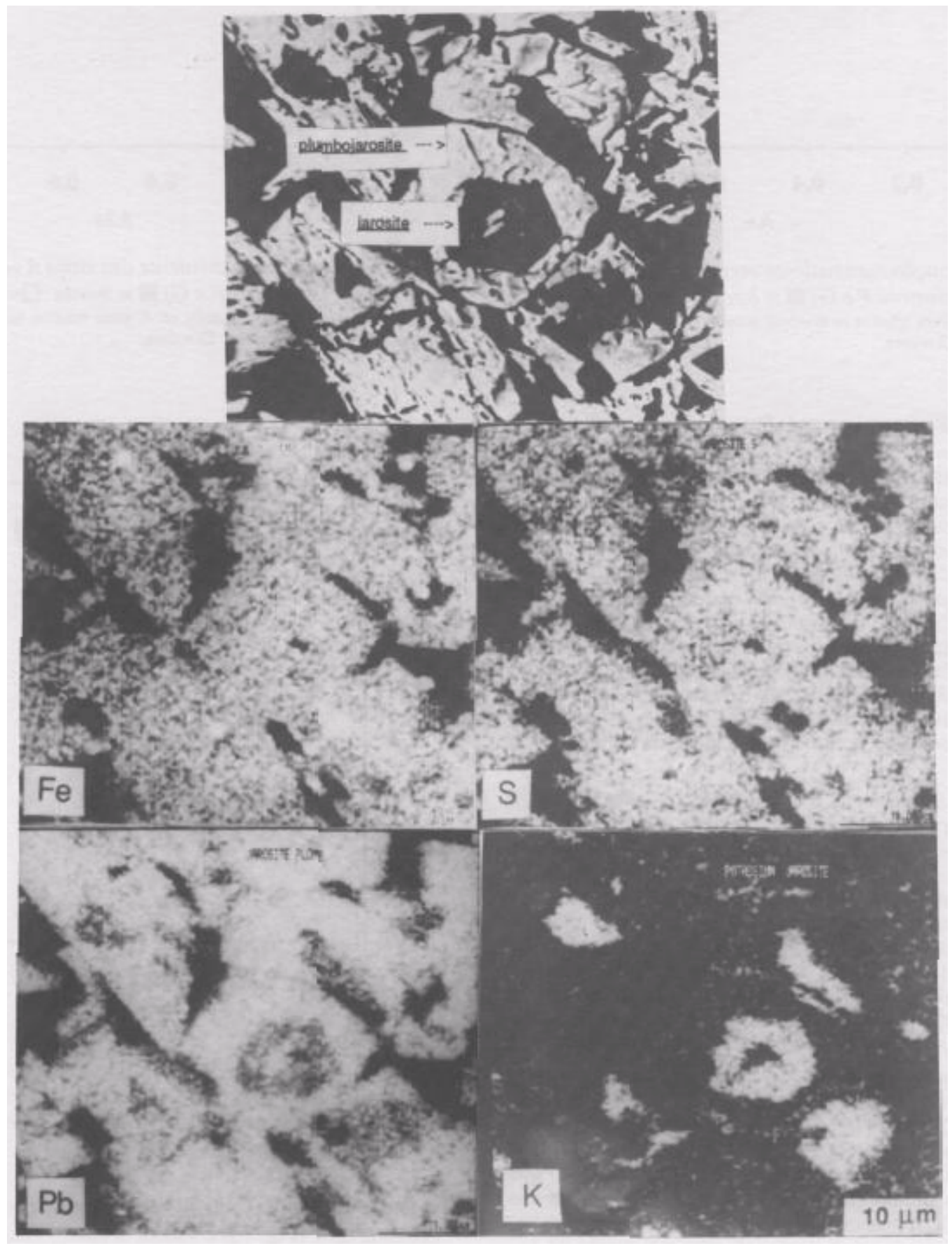

Figura 8 - Micrografias de raios X de um cristal de jarosita.

Figure 8 - X-ray micrographs of a jarosite crystal. 


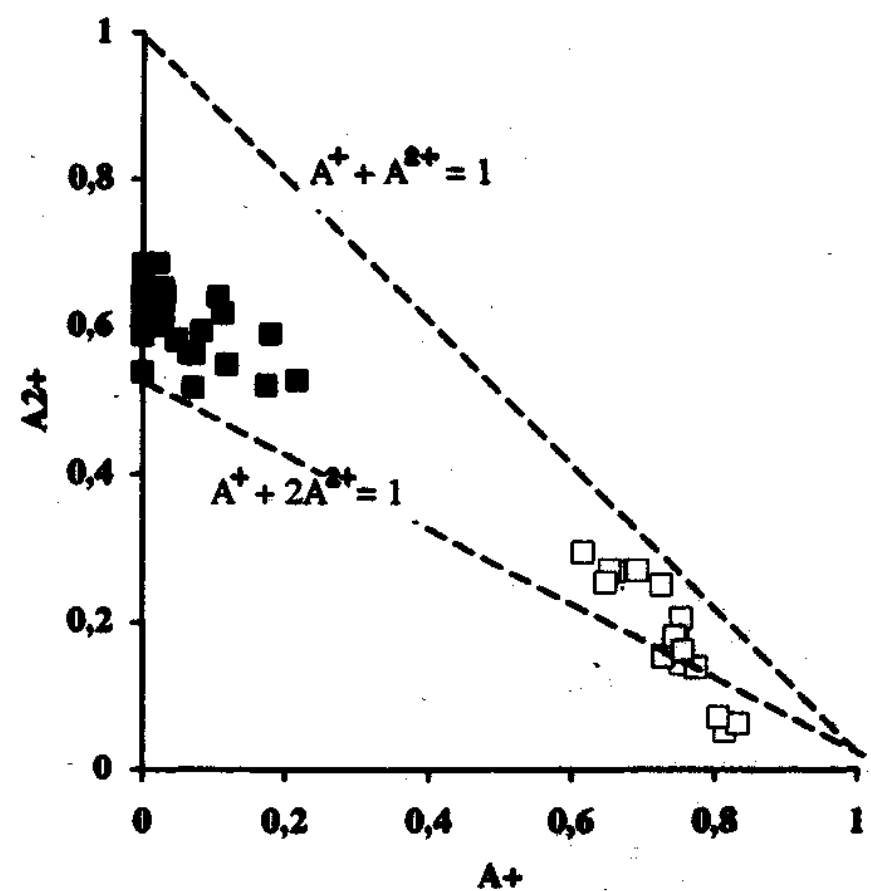

Figura 9 - Ocupação monovalente versus ocupação divalente dos sítios $A$ (amostras $F$ e G) $\mathbf{\square}=$ borda $\square=$ núcleo. Figure 9 - Monovalent relative to divalent occupancy of A sites (samples $F$ and $\mathrm{G}) \mathbf{\square}=\operatorname{rim} \square=$ core.

positivas $(\mathbf{A}+\mathbf{B})$ é geralmente inferior ao valor teórico de 10 (Tab. 3).

Se considerarmos a fórmula teórica dos minerais da família da alunita-jarosita $\mathrm{AB}_{3}\left(\mathrm{SO}_{4}\right) 2(\mathrm{OH})_{6}$, somente poderemos ter $\mathrm{Pb}^{2+}$ em A ocupando mais de $50 \%$ dos sities, se houver substituição compensatória em $\mathbf{B}$, com um cátion bivalente substituindo o cátion trivalente $\left(\mathrm{Zn}^{2}\right.$ substituindo $0 \mathrm{Fe}^{3+}$, por exemplo), ou substituicão compensatória do ânion $\mathrm{XO}_{4}^{2 i 1}$ por um ânion $\mathrm{XO}_{4}^{3-}\left(\mathrm{PO}_{4}^{3-}\right.$ substituindo $\mathrm{SO}_{4}^{2-}$, por exemplo). No caso das jarositas de Canoas, isso não acontece, pois em $\mathrm{B}$ há muito pouco $\mathrm{Zn}^{2+}$ substituindo o $\mathrm{Fe}^{3+}$ e em $\mathrm{XO}_{4}$, só muito raramente, há algum $\mathrm{P}$ substituindo $\mathrm{O} S$, e ainda assim há mais de $50 \%$ dos sítios ocupados pelo $\mathrm{Pb}^{2+}$. $\mathrm{O}$ excesso de carga, nesse caso, poderia ser compensado pela perda de um próton do ânion ${ }^{-0} \mathrm{H}$.

Com relação à vacância e à deficiência de carga em $\mathbf{B}$, a literatura mostra que são bastante comuns, seja em jarositas, seja em plumbojarositas, naturais ou sintéticas (Dutrizac \& Kaiman 1976; Jambor \& Dutrizac 1983; Szymaski 1985). Esse último autor levantou a hipótese segundo a qual essas deficiências poderiam ser atribuídas, pelo menos parcialmente, ao método de cálculo, que toma por base $\mathrm{S}=2$, sendo 0 enxofre um dos elementos analisados com menor precisão, tanto pêlos métodos clássicos, como pela rnicrosssonda. Em resumo, os persistentes desvios da estequiometria ideal nas jarositas não encontram explicação totalmente satisfatória.

A tabela 4 mostra os dados relativos ao número de átomos referidos a $\mathrm{S}+\mathrm{P}=2$ para pontos analisados nas lâminas das amostras C e D. Em C, trata-se de cristais mais homogéneos, ricos ao mesmo tempo em $\mathrm{Pb}^{2+}$ e K , enquanto, em D, são jarositas com muito pouco $\mathrm{Pb}$ (Fig. 12). A exemplo do que ocorre com as plumbojarositas das bordas dos cristais das amostras $\mathrm{F}$ e $\mathrm{G}$, os pontos analisados em $\mathrm{C}$ também apresentam excesso de carga em A, crescente com o aumento de $\mathrm{A}^{2+}$ (Fig. 13), e vacância em torno de $10 \%$ (Tab. 4). Em B, há igualmente vacância (Tab. 4) e deficiência de carga (Fig. 14). Também nesse caso, o total das cargas positivas é inferior ao

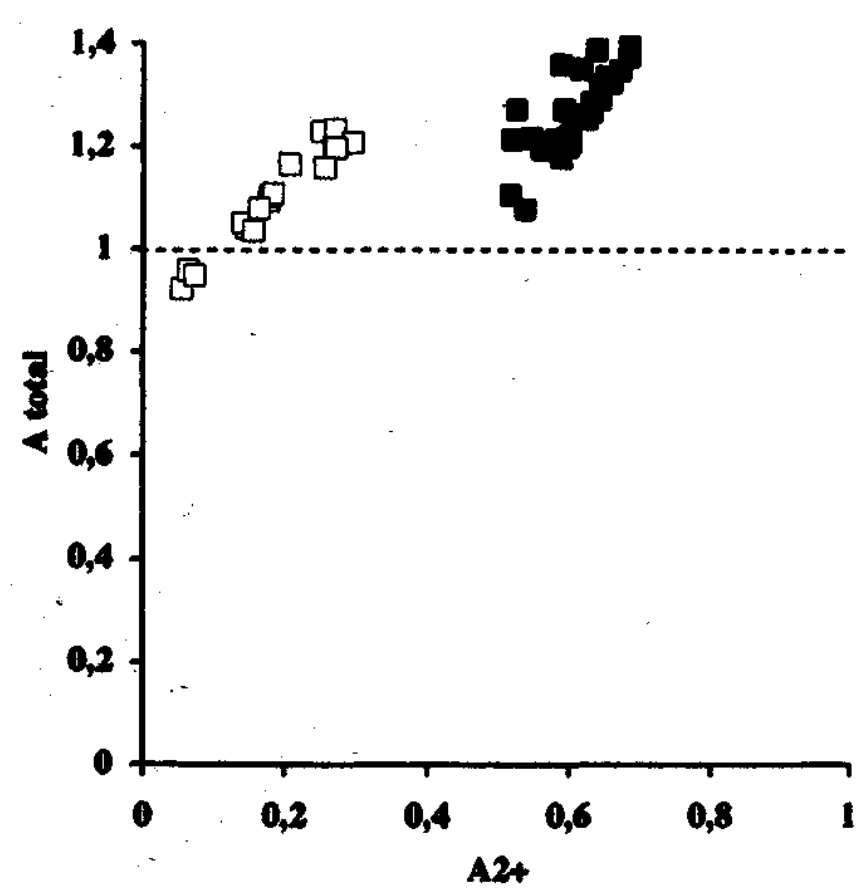

Figura JO - Ocupação divalente dos sítios A versus ocupação dos sitios $A$ (amostras $F$ e $G$ ) $M=$ borda $\mathrm{D}=$ núcleo. Figure 10 - Divalent occupancy of A sites relative to A-site occupancy (samples $\mathrm{F}$ and $\mathrm{G}) \cdot=$ rim $\mathrm{D}=$ core.

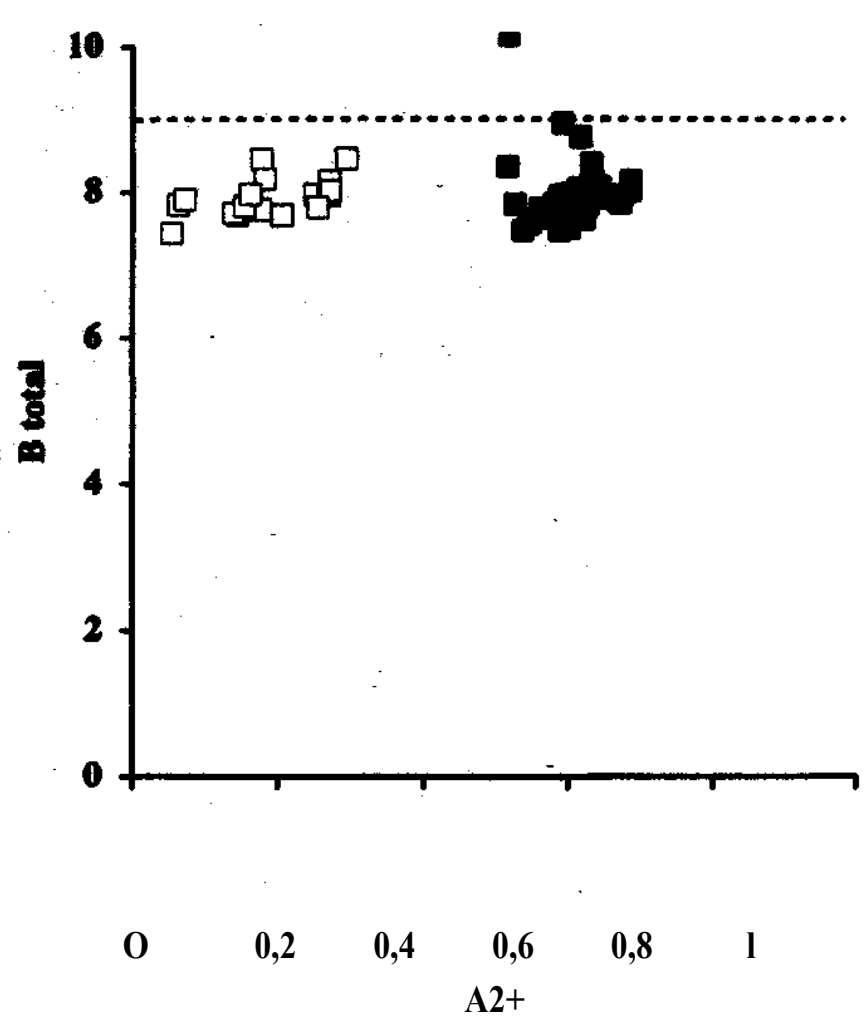

Figura 11 - Ocupação divalente dos sítios A versus ocupação dos sítios $B$ (amostras $F$ e G) $\mathbf{\square}$ - borda $\square=$ núcleo. Figure lí - Divalent occupancy of A sites relative to B-site occupancy (samples $F$ and $G$ ) $\boldsymbol{\square}=$ rim $\square=$ core.

valor teórico de 10 (Tab. 4). As amostras D têm em A carga próxima de 1 (Fig. 13) e vacância baixa, geralmente inferior a $10 \%$ (Tab. 4). Em B, chegam a apresentar excesso de carga (Fig. 14) e um super preenchimento dos sítios (ocupância $>3$, Tab. 4), o que pode ser atribuído à contaminação por goethita. 
Tabela 3 - Fórmulas estruturais baseada em $2\left(\mathrm{SO}_{4}, \mathrm{PO}_{4}\right)$, calculada a partir de análises EDS para as amostras $\mathrm{F}$ e $\mathrm{G}$ ( $b=$ borda, $n=$ núcleo).

Table 3 - Structural formulae based on $2\left(\mathrm{SO}_{4}, \mathrm{PO}_{4}\right)$, calculated from EDS analyses $(\mathrm{b}=\mathrm{rim}, \mathrm{n}=$ core). Samples $\mathrm{F}$ and $\mathrm{G}$.

\begin{tabular}{|c|c|c|c|c|c|c|c|c|c|c|c|c|c|c|}
\hline Amostra & & $\mathbf{K}^{+}$ & $\mathrm{Na}^{+}$ & $\mathrm{Pb}^{2+}$ & $\begin{array}{c}\text { A } \\
\text { ocupancia }\end{array}$ & $\begin{array}{c}\text { A } \\
\text { carga }\end{array}$ & $\mathrm{Zn}^{2 *}$ & $\mathrm{Al}^{3 *}$ & $\mathrm{Fe}^{2+}$ & $\begin{array}{c}\text { B } \\
\text { ocupancia }\end{array}$ & $\begin{array}{c}\text { B } \\
\text { carga }\end{array}$ & $\begin{array}{l}\mathrm{A}+\mathrm{B} \\
\text { carga }\end{array}$ & $S$ & $\mathbf{P}$ \\
\hline F145 & $\mathbf{b}$ & 0.020 & 0.000 & 0.621 & 0.641 & 1.261 & 0.078 & 0.059 & 2.478 & 2.616 & 7.769 & 9.030 & 2 & 0 \\
\hline F146 & $\mathbf{b}$ & 0.017 & 0.000 & 0.622 & 0.639 & 1.261 & 0.000 & 0.052 & 2.492 & 2.544 & 7.633 & 8.895 & 2 & 0 \\
\hline F147 & $\mathbf{b}$ & 0.119 & 0.000 & 0.548 & 0.667 & 1.215 & 0.000 & 0.000 & 2.521 & 2.521 & 7.563 & 8.778 & 2 & 0 \\
\hline F148 & $\mathbf{b}$ & 0.000 & 0.000 & 0.589 & 0.589 & 1.177 & 0.000 & 0.000 & 2.486 & 2.486 & 7.458 & 8.636 & 2 & 0 \\
\hline F149 & $\mathbf{b}$ & 0.000 & 0.000 & 0.627 & 0.627 & 1.253 & 0.000 & 0.000 & 2.598 & 2.598 & 7.793 & 9.047 & 2 & 0 \\
\hline F41 & $\mathbf{b}$ & 0.028 & 0.000 & 0.653 & 0.681 & 1.334 & 0.060 & 0.061 & 2.539 & 2.660 & 7.921 & 9.255 & 2 & 0 \\
\hline F42 & $\mathbf{b}$ & 0.000 & 0.000 & 0.626 & 0.626 & 1.252 & 0.000 & 0.037 & 2.612 & 2.649 & 7.948 & 9.200 & 2 & 0 \\
\hline F43 & $\mathbf{b}$ & 0.048 & 0.000 & 0.582 & 0.630 & 1.212 & 0.000 & 0.000 & 2.612 & 2.612 & 7.837 & 9.049 & 2 & 0 \\
\hline F44 & $\mathbf{b}$ & 0.569 & 0.000 & 0.316 & 0.885 & 1.201 & 0.000 & 0,000 & 3.015 & 3.015 & 9.044 & 10.245 & 2 & 0 \\
\hline F52 & $b$ & 0.021 & 0.000 & 0.687 & 0.708 & 1.394 & 0.000 & 0.000 & 2.714 & 2.714 & 8.142 & 9.537 & 2 & 0 \\
\hline F53 & $\mathbf{b}$ & 0.083 & 0.000 & 0.594 & 0.677 & 1.271 & 0.000 & 0.053 & 2.927 & 2.980 & 8.939 & 10.209 & 2 & 0 \\
\hline F54 & b & 0.106 & 0.000 & 0.640 & 0.746 & 1.387 & 0.081 & 0.054 & 2.583 & 2.718 & 8.073 & 9.460 & 2 & 0 \\
\hline F5s & b & 0.179 & 0.000 & 0.589 & 0.769 & 1.358 & 0.000 & 0.044 & 2.605 & 2.648 & 7.945 & 9.302 & 2 & 0 \\
\hline F56 & $\mathbf{b}$ & 0.000 & 0.000 & 0.673 & 0.673 & 1.346 & 0.000 & 0.000 & 2.614 & 2.614 & 7.842 & 9.188 & 2 & 0 \\
\hline F57 & b & 0.000 & 0.000 & 0.661 & 0.661 & 1.322 & 0.000 & 0.042 & 2.604 & 2.647 & 7.940 & 9.263 & 2 & 0 \\
\hline F58 & b & 0.019 & 0.000 & 0.633 & 0.651 & 1.284 & 0.000 & 0.000 & 2.792 & 2.792 & 8.377 & 9.660 & 2 & 0 \\
\hline F59 & $b$ & 0.000 & 0.000 & 0.687 & 0.687 & 1.373 & 0.000 & 0.000 & 2.667 & 2.667 & 8.001 & 9.374 & 2 & 0 \\
\hline F60 & $\mathbf{b}$ & 0.000 & 0.000 & 0.633 & 0.633 & 1.267 & 0.000 & 0.000 & 2.711 & 2.711 & 8.132 & 9.399 & 2 & 0 \\
\hline F75 & b & 0.028 & 0.000 & 0.614 & 0.641 & 1.255 & 0.000 & 0.072 & 2.605 & 2.677 & 8.032 & 9.287 & 2 & 0 \\
\hline F78 & b & 0.113 & 0.000 & 0.618 & 0.731 & 1.350 & 0.000 & 0.061 & 2.855 & 2.916 & 8.749 & 10.099 & 2 & 0 \\
\hline F93 & b & 0.018 & 0.000 & 0.602 & 0.619 & 1.221 & 0.000 & 0.000 & 2.501 & 2.501 & 7.502 & 8.723 & 2 & 0 \\
\hline F94 & $\mathbf{b}$ & 0.031 & 0.000 & 0.644 & 0.675 & 1.319 & 0.000 & 0.043 & 2.639 & 2.682 & 8.045 & 9.364 & 2 & 0 \\
\hline F114 & $\mathbf{b}$ & 0.000 & 0.000 & 0.538 & 0.538 & 1.076 & 0.000 & 0.000 & 2.486 & 2.486 & 7.457 & 8.533 & 2 & 0 \\
\hline F115 & $\mathbf{b}$ & 0.000 & 0.000 & 0.603 & 0.603 & 1.207 & 0.000 & 0.051 & 2.604 & 2.655 & 7.965 & 9.172 & 2 & 0 \\
\hline F116 & $\mathbf{b}$ & 0.000 & 0.000 & 0.645 & 0.645 & 1.291 & 0.065 & 0.062 & 2.533 & 2.659 & 7.913 & 9.204 & 2 & 0 \\
\hline F117 & $\mathbf{b}$ & 0.000 & 0.000 & 0.600 & 0.600 & 1.199 & 0.059 & 0.051 & 2.481 & 2.592 & 7.715 & 8.915 & 2 & 0 \\
\hline F118 & $\mathbf{b}$ & 0.216 & 0.000 & 0.527 & 0.743 & 1.270 & 0.000 & 0.050 & 2.559 & 2.609 & 7.827 & 9.097 & 2 & 0 \\
\hline$F 123$ & $\mathbf{b}$ & 0.071 & 0.000 & 0.517 & 0.588 & 1.105 & 0.066 & 0.042 & 2.694 & 2.803 & 8.341 & 9.446 & 2 & 0 \\
\hline F124 & $\mathbf{b}$ & 0.173 & 0.000 & 0.520 & 0.693 & 1.213 & 0.000 & 0.053 & 3.328 & 3.381 & 10.143 & 11.356 & 2 & 0 \\
\hline F150 & $\mathrm{n}$ & 0.814 & 0.000 & 0.054 & 0.868 & 0.922 & 0.000 & 0.000 & 2.477 & 2.477 & 7.430 & 8.351 & 2 & 0 \\
\hline F151 & $\mathbf{n}$ & 0.752 & 0.000 & 0.206 & 0.958 & 1.165 & 0.000 & 0.000 & 2.558 & 2.558 & 7.675 & 8.839 & 2 & 0 \\
\hline F152 & $\mathbf{n}$ & 0.750 & 0.000 & 0.145 & 0.895 & 1.039 & 0.000 & 0.073 & 2.488 & 2.561 & 7.682 & 8.722 & 2 & 0 \\
\hline F153 & $\mathbf{n}$ & 0.741 & 0.000 & 0.176 & 0.918 & 1.094 & 0.000 & 0.099 & 2.486 & 2.585 & 7.754 & 8.848 & 2 & 0 \\
\hline $\mathrm{F} 45$ & $\mathbf{n}$ & 0.724 & 0.000 & 0.251 & 0.976 & 1.227 & $0: 000$ & 0.000 & 2.654 & 2.654 & 7.963 & 9.190 & 2 & 0 \\
\hline F46 & $\mathbf{n}$ & 0.746 & 0.000 & 0.178 & 0.924 & 1.103 & 0.000 & 0.060 & 2,752 & 2.813 & 8.438 & 9.540 & 1.976 & 0.024 \\
\hline F47 & $\mathbf{n}$ & 0.832 & 0.000 & 0.063 & 0.895 & 0.958 & 0.000 & 0.000 & 2.610 & 2.610 & 7.830 & 8.788 & 2 & 0 \\
\hline F48 & $\mathbf{n}$ & 0.772 & 0.000 & 0.139 & 0.912 & 1.051 & 0.000 & 0.042 & 2.526 & 2.568 & 7.704 & 8.755 & 2 & 0 \\
\hline F49 & $\mathbf{n}$ & 0.659 & 0.000 & 0.270 & 0.929 & 1.199 & 0.000 & 0.000 & 2.652 & 2.652 & 7.957 & 9.156 & 2 & 0 \\
\hline F50 & $\mathbf{n}$ & 0.690 & 0.000 & 0.271 & 0.961 & 1.232 & 0.000 & 0.035 & 2.680 & 2.715 & 8.146 & 9.378 & 2 & 0 \\
\hline F51 & $\mathbf{n}$ & 0.615 & 0.000 & 0.295 & 0.910 & 1.205 & 0.000 & 0.038 & 2.778 & 2.816 & 8.448 & 9.653 & 2 & 0 \\
\hline F76 & $\mathbf{n}$ & 0.804 & $\mathbf{0 . 0 0 0}$ & 0.072 & 0.876 & 0.948 & 0.000 & 0.083 & 2.550 & 2.632 & 7.897 & 8.845 & 2 & 0 \\
\hline F81 & $\mathbf{n}$ & 0.727 & 0.000 & 0.154 & 0.881 & 1.035 & 0.000 & 0.080 & 2.518 & 2.598 & 7.794 & 8.829 & 2 & 0 \\
\hline F82 & $\mathbf{n}$ & 0.743 & 0.000 & 0.182 & 0.925 & 1.107 & 0.000 & 0.041 & 2.684 & 2.725 & 8.175 & 9.282 & 2 & 0 \\
\hline F84 & $\mathbf{n}$ & 0.652 & 0.000 & 0.272 & 0.924 & 1.196 & 0.000 & 0.034 & 2.637 & 2.670 & 8.011 & 9.207 & 2 & 0 \\
\hline F95 & $\mathbf{n}$ & 0.753 & 0.000 & 0.162 & 0.916 & 1.078 & 0.000 & 0.056 & 2.598 & 2.654 & 7.962 & 9.040 & 2 & 0 \\
\hline F96 & $\mathbf{n}$ & 0.646 & 0.000 & 0.255 & 0.901 & 1.156 & 0.000 & 0.000 & 2.595 & 2.595 & 7.784 & 8.941 & 2 & 0 \\
\hline $\mathrm{G} 1$ & $\mathrm{~b}$ & 0.072 & 0.000 & 0.562 & 0.635 & 1.197 & 0.000 & 0.000 & 2.590 & 2.590 & 7.770 & 8.966 & 2 & 0 \\
\hline G4 & $b$ & 0.065 & 0.000 & 0.564 & 0.629 & 1.193 & 0.000 & 0.000 & 2.549 & 2.549 & 7.647 & 8.840 & 2 & 0 \\
\hline $\mathrm{G} 2$ & $\mathbf{n}$ & 0.715 & 0.000 & 0.194 & 0.909 & 1.103 & 0.000 & 0.000 & 2.637 & 2.637 & 7.912 & 9.015 & 2 & 0 \\
\hline G5 & n & 0.079 & 0.000 & 0.572 & 0.651 & 1.223 & 0.000 & 0.000 & 2.625 & 2.625 & 7.875 & 9.097 & 2 & 0 \\
\hline G6 & n & 0.700 & 0.000 & 0.216 & 0.915 & 1.131 & 0.000 & 0.042 & 2.525 & 2.567 & 7.700 & 8.831 & 1.971 & 0.029 \\
\hline G8 & $\mathbf{n}$ & 0.718 & 0.000 & 0.205 & 0.923 & 1.127 & 0.000 & 0.056 & 2.559 & 2.615 & 7.845 & 8.972 & 2 & 0 \\
\hline G9 & $\mathbf{n}$ & 0.829 & 0.000 & 0.070 & 0.899 & 0.970 & 0.000 & 0.031 & 2.650 & 2.681 & 8.044 & 9.013 & 2 & 0 \\
\hline G26 & $\mathbf{n}$ & 0.702 & 0.000 & 0.220 & 0.921 & 1.141 & 0.000 & 0.054 & 2.648 & 2.701 & 8.104 & 9.245 & 1.961 & 0.039 \\
\hline G27 & $\mathrm{n}$ & 0.662 & 0.000 & 0.279 & 0.941 & 1.220 & 0.000 & 0.0038 & 2.980 & 3.018 & 9.055 & 10.275 & 2 & 0 \\
\hline G28 & $\mathrm{n}$ & 0.274 & 0.000 & 0.703 & 0.977 & 1.680 & 0.000 & 0.037 & 2.639 & 2.676 & 7.928 & 9.608 & 1.978 & 0.022 \\
\hline
\end{tabular}




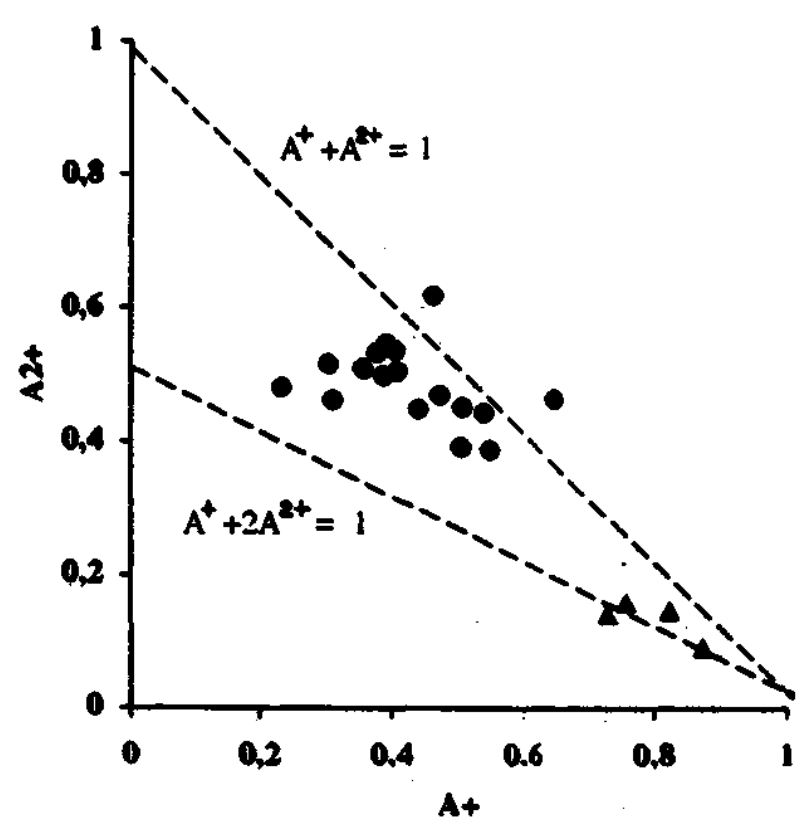

Figura 12 - Ocupação monovalente ver sus ocupação divalente dos sitios $A$ (amostras $C$ e D) $\bullet=\operatorname{amostra} C \mathbf{\Delta}=$ amostra D

Figure 12 - Monovalent relative to divalent occupancy of A sites (samples C

and D). $\bullet$ = sample $\mathrm{C} \boldsymbol{\Delta}$ = sample D

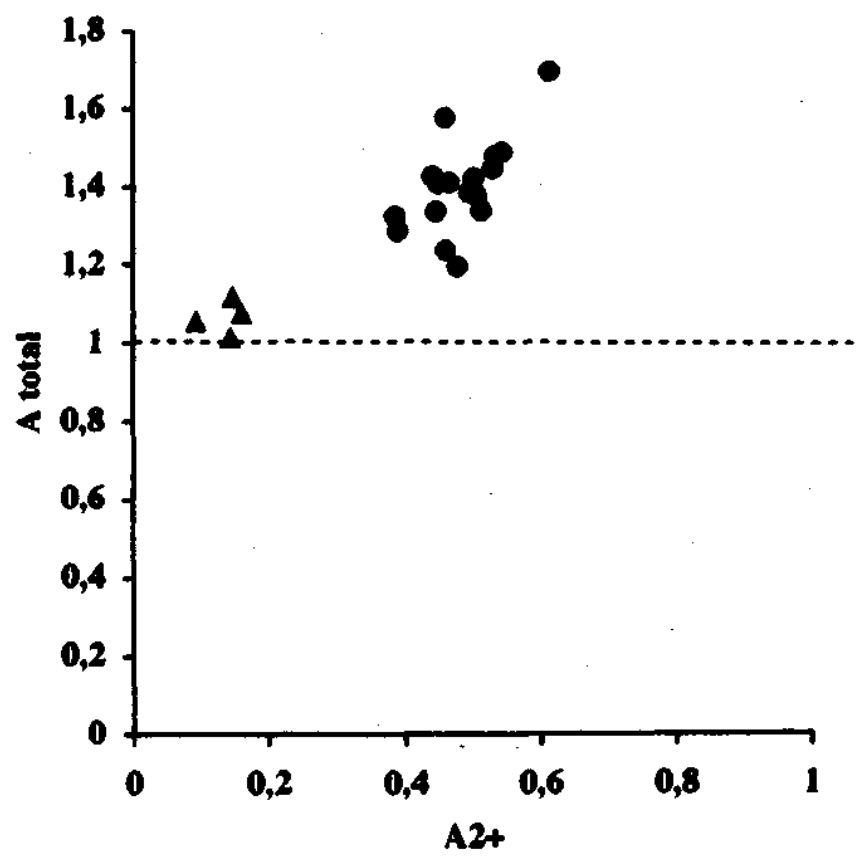

Figura 13 - Ocupação divalente dos sítios A versus ocupação dos sítios $A$ (amostras $C$ è D). $\bullet=$ amostra $C \boldsymbol{\Delta}=\operatorname{amostra} D$ Figure 13 - Divalent occupancy of A sites relative to A-site occupancy (samples $\mathrm{C}$ and $\mathrm{D}$ ). $\bullet=$ sample $\mathrm{C} \boldsymbol{\Delta}=$ sample $\mathrm{D}$

A fórmula estrutural da jarosita da amostra E 506 não parece muito semelhante àquelas analisadas pontualmente nas amostras F, G, C e D. As vacâncias em A de 28\% e em B de $25 \%$ são bastante superiores às vacâncias calculadas para as análises microsituadas de jarositas essencialmente potássicas. Da mesma forma, encontram-se maiores deficiências de carga em A e B na amostra E 506 que nos pontos microanalisados.

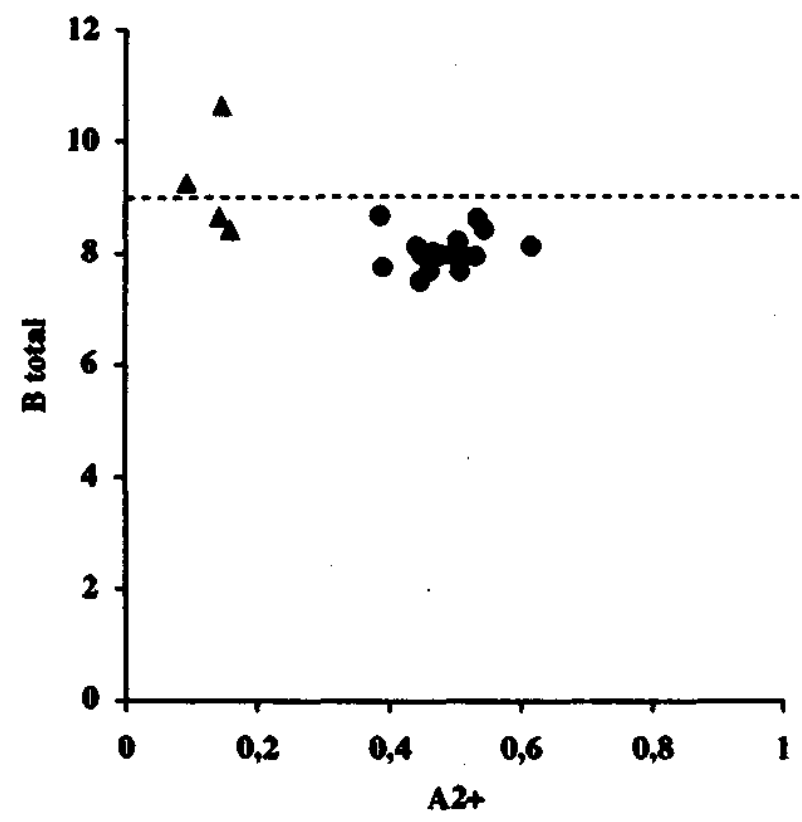

Figura 14 - Ocupação divalente dos sítios A versus ocupação dos sítios $\mathrm{B}$ (amostras $C$ e D). $\bullet=$ amostra $C \boldsymbol{\Delta}=$ amostra $D$ Figure 14 - Divalent occupancy of A sites relative to B-site occupancy (samples $\mathrm{C}$ e D). $\bullet=$ sample $\mathrm{C} \boldsymbol{\Delta}$ = sample D

É possível que se trate de erro analítico para a amostra E 506, pois, em que pese a frequente ocorrência de desvios da fórmula ideal relatada na literatura, no caso dessa amostra essses desvios parecem excessivos.

IMPLICAÇÕES GENÉTICAS As jarositas encontradas nos gossans de Canoas é secundária neoformada a partir da oxidação dos sulfetos primários que teriam fornecido $\mathrm{Fe}$, $\mathrm{S}$ e $\mathrm{Pb}$, e da hidrólise do ortoclásio da ganga que teria fornecido K. A filiação ortoclásio-jarosita foi sugerida pela presença de picos característicos da jarosita que aparecem nos difratogramas que contêm ortoclásio.

O frequente zoneamento dos cristais poderia refletir uma disponibilidade mais tardia do chumbo no processo de alteraçãd intempérica do minério e da ganga. De fato, a observação petrográfica do minério em vias de alteração indica que enquanto a pirita e a esfalerita já estão alteradas, a galena ainda permanece fresca. Assim, o chumbo somente estaria disponível depois que os núcleos jarosíticos estivessem formados, e precipitaria como plumbojarosita em torno deles.

As jarositas encontram-se sempre associadas à goethita, que é também derivada da oxidação da pirita. As relações de equilíbrio entre essas três espécies a $25^{\circ} \mathrm{C}$ e 1 atm foram calculadas por Brown (1971), baseado em dados de energia livre disponíveis na literatura. $\mathrm{O}$ equilíbrio entre jarosita e goethita pode ser assim expresso:

$$
\mathrm{KFe}_{3}\left(\mathrm{SO}_{4}\right)_{2}(\mathrm{OH})_{6} \rightarrow \mathrm{SFeOOH}+\mathrm{K}^{+}+2 \mathrm{SO}_{4}{ }^{2}-+3 \mathrm{H}^{+}
$$

Da análise dos diagramas construídos por Brown (1971), a principal conclusão é que a jarosita é estável a baixo $\mathrm{pH}$ e a Eh moderadamente oxidante. Com a crescente atividade do potássio e do ferro dissolvido, o campo de estabilidade dajarosita aumenta em direção aos Eh menos oxídantes. As atividades do $\mathrm{H}^{+}$e do $\mathrm{SO}_{4}^{2-}$ são críticas para a precipitação da jarosita.

No ambiente natural, essas condições correspondem às águas das minas e das fontes termais, ricas em ferro e em sul-fato, em cuja proximidade as jarositas ocorrem com mais frequência. Nas zonas oxidadas de depósitos sulfetados encai- 
Tabela 4 - Fórmulas estruturais baseada em 2 (SO4, PO4), calculada a partir de análises EDS para as amostras C e D. Table 4 - Structural formulae based on 2 (SO4, PO4), calculated from EDS analyses. Samples C and D.

\begin{tabular}{|c|c|c|c|c|c|c|c|c|c|c|c|c|c|}
\hline Amostra & $\mathrm{K}+$ & $\mathrm{Nat}$ & $\mathrm{Pb} 2+$ & $\begin{array}{c}\text { A } \\
\text { ocupancia }\end{array}$ & $\begin{array}{c}\text { A } \\
\text { carga }\end{array}$ & $\mathrm{Zn} 2+$ & $\mathrm{Al3+}$ & Fe3+ & $\begin{array}{c}\text { B } \\
\text { ocupancia }\end{array}$ & $\begin{array}{c}\text { B } \\
\text { carga }\end{array}$ & $\begin{array}{l}\mathrm{A}+\mathrm{B} \\
\text { carga }\end{array}$ & $S$ & $\mathbf{P}$ \\
\hline $\mathrm{C} 22$ & 0,584 & 0,064 & 0,461 & 1,109 & 1,570 & 0,000 & 0,046 & 2,583 & 2,629 & 7,887 & 9,457 & 2 & 0 \\
\hline C23 & 0,471 & 000 & 0,467 & 0,938 & 1,405 & 0,000 & 0,000 & 2,665 & 2,665 & 7,996 & 9,401 & 2 & 0 \\
\hline $\mathrm{C} 24$ & 0,387 & 0,000 & 0,496 & 0,884 & 1,380 & 0,000 & 0,046 & 2,602 & 2,648 & 7,944 & 9,324 & 2 & 0 \\
\hline $\mathrm{C} 25$ & 0,502 & 0,000 & 0,391 & 0,892 & 1,283 & 0,000 & 0,000 & 2,579 & 2,579 & 7,736 & 9,019 & 2 & 0 \\
\hline C26 & 0,504 & 0,000 & 0,450 & 0,954 & 1,404 & 0,000 & 0,000 & 2,654 & 2,654 & 7,962 & 9,366 & 2 & 0 \\
\hline C27 & 0,438 & 0,000 & 0,446 & 0,885 & 1,331 & 0,000 & 0,000 & 2,491 & 2,491 & 7,474 & $\mathbf{8 , 8 0 5}$ & 2 & 0 \\
\hline C28 & 0,392 & 0,000 & 0,545 & 0,937 & 1,482 & 0,000 & 0,000 & 2,802 & 2,802 & 8,406 & 9,888 & 2 & 0 \\
\hline C29 & 0,463 & 0,074 & 0,442 & 0,979 & 1,421 & 0,000 & 0,000 & 2,704 & 2,704 & 8,112 & 9,533 & 2 & 0 \\
\hline C30 & 0,546 & 0,000 & 0,386 & 0,933 & 1,319 & 0,000 & 0,000 & 2,887 & 2,887 & 8,661 & 9,980 & 2 & 0 \\
\hline $\mathrm{C} 42$ & 0,408 & 0,000 & 0,504 & 0,912 & 1,416 & 0,000 & 0,000 & 2,736 & 2,736 & 8,209 & 9,625 & 2 & 0 \\
\hline $\mathrm{C} 43$ & 0,461 & $0 ; 000$ & 0,615 & 1,076 & 1,691 & 0,000 & 0,080 & 2,622 & 2,703 & 8,108 & 9,798 & 2 & 0 \\
\hline C44 & 0,311 & 0,000 & 0,461 & 0,772 & 1,232 & 0,000 & 0,047 & 2,504 & 2,551 & 7,654 & 8,886 & 2 & 0 \\
\hline C50 & 0,233 & 0,000 & 0,479 & 0,712 & 1,191 & 0,067 & 0,000 & 2,608 & 2,675 & 7,958 & 9,149 & 2 & 0 \\
\hline C55 & 0,305 & 0,100 & 0,534 & 0,939 & 1,474 & 0,000 & 0,062 & 2,804 & 2,866 & 8,599 & 10,073 & 2 & 0 \\
\hline C57 & 0,305 & 0,000 & 0,514 & 819 & 1,333 & 0,000 & 0,000 & 2,639 & 2,639 & 7,916 & 9,249 & 2 & 0 \\
\hline C60 & 0,378 & 0,000 & 0,531 & 0,909 & 1,440 & 0,064 & 0,000 & 2,600 & 2,664 & 7,929 & 9,369 & 2 & 0 \\
\hline C62 & 0,274 & 0,083 & 0,507 & 0,864 & 1,371 & 0,000 & 0,035 & 2,517 & 2,552 & 7,656 & 9,026 & 2 & 0 \\
\hline D 1 & 822 & 0,000 & 0, & 0, & 1,117 & 0,0 & 0,0 & 3,4 & 3,545 & 10,635 & 11,753 & 2 & 0 \\
\hline D 2 & 0,872 & 0,000 & 0,093 & 0,964 & 1,057 & 0,000 & 0,067 & 3,022 & 3,089 & 9,267 & 10,324 & 2 & 0 \\
\hline D 3 & 0,730 & 0,000 & 0,143 & 0,873 & 1,016 & 0,000 & 0,000 & 2,884 & 2,884 & 8,651 & 9,666 & 2 & 0 \\
\hline D 4 & 0,757 & 0,000 & 0,160 & 0,917 & 1,077 & 0,000 & 0,042 & 2,763 & 2,805 & 8,416 & 9,493 & 2 & 0 \\
\hline
\end{tabular}

xados em rochas carbonáticas, $\mathrm{os} \mathrm{pH}$ reinantes são geralmente maiores que 7 , constituindo, portanto, ambientes onde a jarosita não deveria ocorrer. Da mesma forma, nos gossans sujeitos à circulação das águas superficiais ou subterrâneas, de pH entre 5 e 8, a jarosita deveria desaparecer para dar lugar à goethita. Efetivamente, isso acontece, conforme foi demonstrado por Blanchard (1968), através de estudos petrográficos que evidenciam figuras de substituição de jarosita por goethita. Entretanto, a jarosita também pode estar presente e mesmo ser bastante comum nesses ambientes, devido provavelmente aos aspectos cinéticos das reações envolvidas. Ela formar-se-ia no início da alteração da pirita, próxima do minério fresco, em equilíbrio com águas mais ácidas, e permaneceria nos níveis mais lixiviados do perfil de alteração devido à lentidão da reação de transformação jarosita $\rightarrow$ goethita.

Em Canoas, no minério oxidado, ocorrem jarositas e plumbojarositas intimamente associadas à goethita, que também é portadora de $\mathrm{Pb}$. Essa associação em ambiente superficial percolado pelas águas meteóricas representa, à luz das considerações termodinâmicas acima expressas, uma situação de desequilíbrio. Com efeito, essa associação está ausente dos gossans mais maduros, encontrados nos arredores da mina, compostos quase que exclusivamente por goethita e hematita. Assim, na evolução supérgena dos sulfetos de Canoas, a jarosita não passa de uma armadilha provisória para o chumbo, liberado quando da oxidação da galena, o que também é o caso da cerussita e da piromorfita. Com a desestabilização da jarosita nas zonas mais lixiviadas do perfil de alteração, o chumbo é novamente posto em disponibilidade, e vai associar-se aos óxidos e oxi-hidróxidos de ferro dos gossans mais maduros, através de ligações cuja natureza resta a esclarecer.

Agradecimentos Os autores são gratos aos geólogos N. Queiroga e E. C. Daitx pelas facilidades de acesso à mina, à Sra A. Bouleau pelo auxflio no uso do MEV, ao químico E. Balan pela ajuda no uso do programa DBWS-94 11 e aos Profs. H. R. Rechenberg e C.S.de M.Partiti pela aquisição e interpretação do espectro Mössbauer. $\mathrm{O} \mathrm{CNPq}$ forneceu os recursos materiais que tornaram possível este trabalho.

\section{REFERÊNCIAS}

AFANASEV, A. M.; GOROBCHENKO, V. D.; KULGAWCKUC, D. S.; LUKASHEVICH, 1.1.1974. Nuclear y-resonance in iron sulphates of the jarosite group. Phys. Status Solidi, A-26:697-701.

ALLEN, E. T.; DA Y, A. L.; MERWIN, H. E. 1935. Hot springs of the Yellowstone National Park. Carnegie Inst. Wash. Publ. 466.

AMOROS, J. L.; LUNAR, R.; TAVIRA. P. 1981. Jarosite: a silver bearing mineral of the gossan of Rio Tinto (Huelva) and La Union (Cartagena, Spain). Mineral. Deposita, 16:205-213.

BLANCHARD, R. 1968. Interpretation of leached outcrops. Nevada Bureau of Mines Bulletin, 26:1-196.

BROPHY, G. P.; SHERIDAN, M. F. 1964. Sujphate studies IV. The jarosite-natrojarosite-hydronium jarosite solid solution series. Am. Mineral, 49:1596-1607.

BROWN, J. B. 1971. Jarosite-goethite stabilities at $25^{\circ} \mathrm{C}, 1 \mathrm{~atm}$. Mineral. Deposita, 6:245-252.
DUTRIZAC, J. E.; KAIMAN, S. 1976. Synthesis and properties of jarosite-type compounds. Can. Mineral.,14:151-15\&.

DAITX, E. C.; VENUSSO, G. C. 1992. Geologia preliminar da jazida de Canoas (Pb-Zn-Ag-Ba), Vale do Ribeira, PR. In: CONGR. BRÁS. GEOL., 36, São Paulo, 1992. Boi. Rés. Exp... São Paulo, SBG. p. $253-255$

FORSYTH, J. B.; HEDLEY, I. G.; JOHNSON, C. E. 1968. The magnetíc structure and the hyperfine field of goethite (otFeOOH). J.Phys. C., 1:179-188

HENDRICKS, S. B. 1937. The crystal structure of alunite and the jarosites. Am. Mineral, 22:773-784.

JAMBOR, J. L.; DUTRIZAC, J. E. 1983. Beaverita-plumbojarosite solid solutions. Can. Mineral., 21:101-113. 
JOHNSTON, J.H. 1977. Jarosite and akaganeite from White Island voicano. New Zealand: an X-ray and Mössbauer study. Geoch. Cosmoch. Acta, 41:539-544.

KATO, T.; MIURA, Y. 1977. The crystal structurcs of jarosite and svanbergite. Mineral. Journal, 8(8):419-430.

KULP, J. L.; ADLER. H. H. 1950. Thermal study of jarosite. Am. J. Science, 248:475-487.

KUNDIG, W.; BOMMEL, H.; CONSTABARIS, G.; LINDQUIST, R. H. 1966. Some properties of supported small $\alpha \mathrm{Fe}_{2} \mathrm{O}_{3}$ particles determined with the Mössbauer effect. Phys. Rev., 142:327-333.

LECLERC, A. 1980. Room temperatura Mössbauer analysis af jarosite-type componnds. Phys. Chem. Min., 6:327-334.

OLIVEIRA, S. M. B. DE; MAGAT, P.; BLOT, A. 1993. O gossan de Irecê-Lapão (BA). Geoch. Brasil., 7 (2):131-149.

SCOTT, K. M. 1987. Solid solution in, and classification of, gossan-derived members of the alunite-jarosite family, northwest Queensland, Austrália. Am. Mineral., 72:178-187.
SZYMÁNSKI, J. T. 1985. The crystal structure of plumbojarosite $\mathrm{Pb}\left[\mathrm{Fe}_{3}\left(\mathrm{SO}_{4}\right)_{2} \mathrm{OH}\right)_{6}$. Can. Mineral., 23:659-668.

TAKANO, M.; SHINJO, T.; KIYAMA, M.; TAKADA, T. 1968. Magnetic properties of jarosites, $\mathrm{RFe}(\mathrm{OH})_{6}\left(\mathrm{SO}_{4}\right)_{2}\left(\mathrm{R}=\mathrm{NH}_{4}, \mathrm{Na}\right.$ or K $)$. J.Phys. Soc. Jpn., 25:902

TAYLOR, G. F.; APPLEYARD, E. C. 1983. Weathering of the zinc-lead Iode, Dugald River, Northwest Queensland: I.The gossan profile. $J$. Geoch. Expl. 18:87-110.

YOUNG, R. A.; SAKTHIEVEL, A.; MOSS, T. S. S.; PAIVA-SANTOS, C.0.1995. User's guide to program DBWS-9411 for Rietveld analysis of X-ray and neutron powder diffraction patterns, $61 \mathrm{p}$.

Manuscrito A845

Recebido em 29 de abril de 1996

Revisã 0 do autor en 19 de setembro de 1996 Revisão aceita em 20 de setembro de 1996 